\title{
BIBLIOGRAFIA PUBLIKACJI PROF.DR HAB. BARBARY BIEŃKOWSKIEJ w układzie chronologicznym
}

(zestawiła Krystyna Wojakowska)

1960

1. Decjusz J.L.: Księga o czasach króla Zygmunta. Warszawa: Państ. Wydawn. Nauk., 145 s. (przekład z języka łacińskiego wspólnie z J. Baryń i innymi)

2. W teatrze greckim = Mówią Wieki, nr 1, s. 34-37

1962

3. Księgozbiór byłego Towarzystwa Naukowego Warszawskiego = Studia i Materiały z Dziejów Nauki Polskiej, Seria A, z. 6, s. 49-134 (współautor Z. Sidorowicz)

\section{3}

4. Bibliografia zagadnień polityki kulturalnej na rok 1960, dodatek do czasopisma "Kultura i Spoleczeństwo", t. 7, $115 \mathrm{~s}$. (współautor)

\section{4}

5. Bibliografia zagadnień polityki kulturalnej na rok 1961, toż t. 8, $88 \mathrm{~s}$. (współautor)

6. Tymon Ateńczyk albo kariera Mizantropa = Mówią Wieki, nr 2, s. 6-9

\section{5}

7. Amerykańskie Stowarzyszenie Postępu Nauki AAAS = Zagadnienia Naukoznawstwa, z. 4, s. $129-130$

\section{6}

8. Nad kroniką Bernarda Wapowskiego. Opis lat 1516-1528i jego źródło-kronika Emeryka Węgra = Studia Źródłoznawcze, t. 11, s. 112-126

9. Polska Bibliografia Naukoznawstwa i Ruchu Naukowego. Rok 1963. Wroctaw: Zakł. Nar. im. Ossolińskich, 407 s. (redakcja naukowa)

10. W kręgu Miechowity i Wapowskiego = Studia i Materiały z Dziejów Nauki Polskiej, Seria A, z. 10, s. 13-32

11. Wydawnictwa informacyjne Międzynarodowej Rady Unii Naukowych = Zagadnienia Naukoznawstwa, 2. 1/2, s. 189-193

\section{7}

12. Polonica $w_{n}$ Nouvelles Extraordinaires" $z$ lat 1706-1714 = Rocznik Historii Czasopiśmiennictwa Polskiego, t. 6, z. 2, s. 5-9 (współautor Z. Sidorowicz) 


\section{8}

13. Polska Bibliografia Naukoznawstwa i Ruchu Naukowego. Rok 1964. Wroclaw: Zakł. Nar. im. Ossolińskich, 395 s. (wspólautor i redakcja naukowa)

\section{9}

14. Kronika Emeryka Węgra (1516-1531) jako źródło Wapowskiego. Wrocław: Zakł. Nar. im. Ossolińskich, 271 s. = Monografie z Dziejów Nauki i Techniki. T. 58

\section{1}

15. Hasła dotyczące historii bibliotek. W: Encyklopedia Wiedzy o Książce. Wrocław: Zakł. Nar, im. Ossolińskich

16. Kopernik i heliocentryzm w polskiej kulturze umystowej do końca XVIII wieku. Wrocław: Zakł. Nar. im. Ossolińskich, 293 s. = Studia Copernicana III

\section{2}

17. From Negation to Acceptance. W: Studia Copernicana V. Wrocław: Zakt. Nar. im. Ossolińskich, s. 79-115

18. Postępowe nurty $w$ polskim szkolnictwie XVII i pierwszej polowy XVIII wieku = Przegląd Historyczno-Oświatowy, nr 3, s. 347-376 (wspólautor T. Bieńkowski)

19. Szkolna recepcja teorii Kopernika $w$ Polsce $w$ XVII i XVIII wieku = Przeglad HistorycznoOświatowy, nr 4, s. 575-611

20. Z dziejów nauczania heliocentryzmu w Polsce = Nowa Szkoła, nr 7/8, s. 7-10

21. Z dziejów recepcji heliocentryzmu w polskich szkołach katolickich od XVi do XVIII wieku = Studia Warmińskie, t. 9, s. 261-312

\section{3}

22. From Negation to Acceptance, W: The Reception of Copernicus Heliocentric Theory. Dordrecht: D. Reidel, s. 79-115

23. Hasła dotyczące dziejów heliocentryzmu. W: Kopernik, astronomia, astronautyka. Przewodnik encyklopedyczny. Warszawa: Państ. Wydawn. Nauk.

24. The Heliocentric Controversy in European Culture. W: Scientific World of Copernicus, Dordrecht: D. Reidel, s. 119-132

25. Iz istorije prihvatanja heliocentrične teorije u Polskoj = Dialektika, Beograd, $\mathrm{nr} 2, \mathrm{~s}$. 103-117

26. Kjerunki recepcji nowożytnej myśli naukowej w szkołach polskich (1600-1773). Cz. 1. Przyrodoznawstwo. Warszawa: Wydawn. UW, $118 \mathrm{~s}$. (wspólautor T. Bieńkowski)

27. Kopernikusz es kora. Budapest: Gondolat, 203 s. (redakcja naukowa) [wersja węgierska poz. 23-24]

28. Nicolas Copernico en el quinto centenario de su nacimiento 1473-1973. Buenos Aires: Siglo XXI. Argentina Editores S.A., 189 s. (redakcja naukowa) [wersja hiszpańska poz. 23-24]

29. Nowożytna myśl naukowa w programach i podręcznikach Komisji Edukacji Narodowej. Nauki matematyczno-przyrodnicze. W: Nowożytna myśl naukowa w szkołach KEN. Wrocław: Zakł. Nar. im. Ossolińskich, s. 31-211

30. Problematyka kopernikańska $w$ polskich księgozbiorach szkolnych $X V \mid-X V I I I$ wieku = Studia o Książce, t. 4, s. 63-77 
31. Przedmioty matematyczno-przyrodnicze w szkołach $\mathrm{KEN}=$ Nowa Szkoła, $\mathrm{nr}$ 7/8, s. 3-34

32. Rola Komisji Edukacji Narodowej w recepcji nowożytnej myśli naukowej w Polsce = Czlowiek i Nauka, s. 280-316 (współautor)

33. The Scientific World of Copernicus. Dordrecht: D. Reidel, $142 \mathrm{~s}$. (redakcja naukowa)

34. W kręgu polskich sporów o heliocentryzm = Komunikaty Instytutu Baltyckiego, z. 18, s. 3-18

35. Z dziejów recepcji nowożytnej myśli naukowej $w$ szkołach polskich XVII-XVIII wieku = Studia i Materialy z Dziejów Nauki Polskiej. Seria E, z. 5, s. 51-116 (wspólautor T. Bieńkowski)

\section{4}

36. Uniwersytet Warszawski 1945-1965. Materialy bibliograficzne. Warszawa: Wydawn. UW, 361 s. (Współredakcja)

\section{5}

37. Polscy pisarze i uczeni XVI-XVIII wieku wobec problematyki ksiażki. W: Dawna książka i kultura. Materialy sesji naukowej z okazji 500-lecia sztuki drukarskiej w Polsce. Wrocław: Zakł. Nar. im. Ossolińskich s. 304-315

38. Some Remarks on the Reception of the Heliocentric Theory from the 17th to the 18th Century. W: Studia Copernicana XIV. Wroclaw: Zakł. Nar. im. Ossolińskich, s. 7-81

39. Z badań nad polskimi księgozbiorami historycznymi. Z. 1. Warszawa: Wydawn. UW, 219 s. (redakcja naukowa)

40. [Rec.] Księga pamiątkowa 400-lecia Toruńskiego Gimnazjum Akademickiego. T. 3 $(X \mid X-X X$ w.). Pod redakcją Z. Zdrójkowskiego. Toruń: Komitet Obchodu...1974. = Kwartalnik Historii Nauki i Techniki, nr 3/4, s. 566-568

\section{6}

41. Kierunki recepcji nowożytnej myśli naukowej w szkołach polskich (1600-1773). Cz. 2. Humanistyka. Warszawa: Wydawn. UW, 111 s. (współautor T. Bieńkowski)

42. Staropolski świat książek. Wrocław: Zakł. Nar. im. Ossolińskich, 262 s.

43. Z badań... Z. 2. Warszawa: Wydawn. UW, 168 s. (redakcja naukowa)

\section{7}

44. Z badań... Z. 3. Warszawa: Wydawn. UW, 236 s. (redakcja naukowa)

\section{8}

45. Aleksandra Birkenmajera koncepcja historii książki = Przegląd Biblioteczny, z. 2, s. $155-162$

\section{0}

46. Z badań... Z. 4. Książka rękopiśmienna. Warszawa: Wydawn. UW, 204 s. (redakcja naukowa)

\section{1}

47. History of Culture - Its Function in Teaching History of Science. W: Problems of Teaching the History of Science Studies of Czechoslovak and Polish Historians of Science for 16th. International Congress of the History of Science. Prague: Ustav československych a svĕtovych dejin CSAV, s. 513-552 
48. Z badań... Z. 5. Szkice i materiały. Warszawa: Wydawn. UW, 176 s. (redakcja naukowa)

49. Z badań... Z. 6. Księgozbiory miejskie i mieszczańskie. Warszawa: Wydawn. UW, 214 s. (redakcja naukowa)

\section{2}

50. [Rec.] Bogdan Suchodolski: Dzieje kultury polskiej. Warszawa: Interpress $1980=$ Kwartalnik Historii Nauki i Techniki, nr 3/4, s. 703-707

\section{3}

51. Biblioteka stanislawowska na tle polskich tradycji kolekcjonerskich. W: Francja - Polska XVIII-XIX. Studia z dziejów kultury i polityki poświęcone Profesorowi Andrzejowi Zahorskiemu w sześćdziesiątą rocznicę urodzin. Warszawa: Państ. Wydawn. Nauk., s. 193198

52. Wiedza o dawnej książce. Przegląd $\mathrm{i}$ ocena literatury dydaktycznej = Przegląd Biblioteczny, z. 2/3, s. 199-205

53. Głos w dyskusji nt. Akademickie kształcenie bibliotekarzy = Przegląd Biblioteczny, z. 2/3, s. 123,172

\section{4}

54. Współautorzy Kazimierz Kontrym i Józef Zawadzki = Księgarz, nr 1, s. 10-14

55. [Rec.] Dzieje nauczania historii nauki i historii techniki w Polsce. Pod redakcją Ireny Stasiewicz-Jasiukowej. Wroclaw: Zakł. Nar. im. Ossolińskich, 1982. = Kwartalnik Historii Nauki i Techniki, nr 2, s. 467-470

\section{5}

56. Edukacja historyczna $w$ akademickim ksztakceniu bibliotekarzy = Roczniki Biblioteczne, z. $1 / 2$, s. $532-545$

57. W sprawie edycji źródeł do historii książki polskiej. W: Z badań... Z. 7, s. 5-9

58. Wprowadzenie do sesji na temat uniwersyteckiego kształcenia pracowników bibliotek szkolnych [Warszawa 13 kwietnia 1984] = Przegląd Biblioteczny, z. 2, s. 165-166

59. Z badań... Z. 7. Badania źródłowe. Warszawa: Wydawn. UW, 185 s. (redakcja naukowa)

60. Z badań... Z. 8. Zbiory specjalne. Warszawa: Wydawn. UW, 135 s. (redakcja naukowa)

\section{6}

61. Kilka uwag i propozycji w sprawie badań księgozbiorów historycznych = Studia o Książce, t. 16 , s. 3-17

62. Kultura umysłowa. W: Warszawa wieku Oświecenia. Pod redakcją Andrzeja Zahorskiego. Wroclaw: Zakł. Nar. im. Ossolińskich, s. 119-148

63. Z badań... Z. 9. Fragmenty i rekonstrukcje. Warszawa: Wydawn. UW, 223 s. (redakcja naukowa)

\section{7}

64. Joachim Lelewel -księgoznawca - bibliotekarz - bibliograf = Kronika Warszawy, nr 3/4, s. $203-207$

65. 35-lecie Instytutu Bibliotekoznawstwa i Informacji Naukowej Uniwersytetu Warszawskiego = Poradnik Bibliotekarza, nr 3, s. 35

66. Zarys dziejów książki. Warszawa: Wydawn. Spółdz., 434 s. (wspólautor H. Chamerska) 
67. [Rec.] R. Cybulski: Książka współczesna. Wydawcy - rynek - odbiorcy. Warszawa: Państ. Wydawn. Nauk., 1986 = Przegląd Humanistyczny, nr 9, s. 169-173

\section{8}

68. Badania regionalne $w$ historiografii książki = Studia o Książce, t. 17, s. 17-33

69. Biblioteka OO.Paulinów w Leśnej (1727-1864) = Studia Claromontana, t. 9, s. 400-414

70. Sprawozdanie z obrad sekcji badań naukowych i ksztalcenia bibliotekarzy [IX Zjazd Bibliotekarzy Polskich, Warszawa 1987] = Bibliotekarz, nr 1-2, s. 15-17

71. Z badań... Z. 10. Warsztaty. Warszawa: Wydawn. UW, 197 s. (redakcja naukowa)

1989

72. Czas próby. Studia bibliotekoznawcze w Uniwersytecie Warszawskim po trzydziestu latach = Kronika Warszawy, nr 2, s. 185-196

73. Inwentarze księgozbiorów prywatnych jako źródła do badań nad dziejami czytelnictwa = Studia o Książce, t. 18, s. 65-76

74. Kultura jaka będzie? Wywiad opracowała $H$. Guzowska $=$ Zorza, nr 52/53, s. 13

75. Metody bibliologiczne $w$ badaniach dziejów nauki = Kwartalnik Historii Nauki i Techniki, nr 2, s. 331-342

76. Miejsce i rola Instytutu Bibliotekoznawstwa i Informacji Naukowej w kształceniu pracowników ksiażki oraz w badaniach bibliologicznych. W: Kształcenie akademickie w zakresie księgoznawstwa, bibliotekoznawstwa i informacji naukowej-przeszłość, teraźniejszość i przyszłość. Redakcja naukowa J. Wojakowski. Warszawa: Wydawn. UW, s. 9-12

77. [Rec.] I. Stasiewicz-Jasiukowa: Onufry Kopczyński współpracownik Komisji Edukacji Narodowej. Studium spolecznej roli uczonego w Polsce stanisławowskiej. Wroclaw: Zakł. Nar. im. Ossolińskich, 1988 = Studia o Książce, t. 18, s. 320-324

\section{0}

78. Books in Poland. Past and Present. Wiesbaden: Otto Harrassowitz, 110 s. (wspólautor Halina Chamerska)

79. Wokół problemów polskiej książki. Wywiad opracowała H. Guzowska = Słowo Powszechne, nr 14, s. 6

80. [Rec.] A. Kawecka-Gryczowa: Biblioteka ostatniego Jagiellona. Pomnik kultury renesansowej. Wroclaw: Zakł. Nar. im. Ossolińskich, 1988 = Kwartalnik Historyczny, 1989 (wyd. $1990)$, nr $3 / 4$, s. $209-213$

\section{1}

81. Z badań... Z. 11. Pogranicza. Warszawa: Wydawn. UW, 274 s. (redakcja naukowa) 1992

82. Czterdzieści lat Katedry Profesora Aleksandra Birkenmajera = Kwartalnik Historii Nauki i Techniki, nr 3, s. 65-94

83. Tysiąc lat książki i bibliotek w Polsce. Wrocław: Zakł. Nar. im. Ossolińskich, 210 s. (współautor Halina Chamerska)

84. Z badań... Z. 12. Z różnych epok. Warszawa: Wydawn. UW, 215 s. (redakcja naukowa)

85. Z badań... Z. 13. Kolekcje wyznaniowe. Warszawa: Wydawn. UW, 215 s. (redakcja naukowa) 
86. Z badań... Z. 14. Wyniki i perspektywy. Warszawa: Wydawn. UW, 247 s. (redakcja naukowa)

87. [Rec.] J. Maternicki: Historiografia i kultura historyczna. Studia i szkice. T. 1-2. Warszawa: Wydawn. UW, $1990=$ Kwartalnik Historii Nauki i Techniki, nr 2, s. 144-147 